\begin{tabular}{|c|l|}
\hline Title & Minority carrier diffusion length in GaN: Dislocation density and doping concentration dependence \\
\hline Author(s) & Kumakura, K.; Makimoto, T.; Kobay ashi, N.; Hashizume, T.; Fukui, T.; Hasegawa, H. \\
\hline Citation & $\begin{array}{l}\text { A pplied Physics Letters, 86, 052105 } \\
\text { https://doi.org/10.1063/1861116 }\end{array}$ \\
\hline Issue Date & $2005-01$ \\
\hline Doc URL & http://hdl.handle.net/2115/5537 \\
\hline Rights & Copyright $\odot 2005$ A merican Institute of Physics \\
\hline Type & article \\
\hline File Information & APL86-5.pdf \\
\hline
\end{tabular}

Instructions for use 


\title{
Minority carrier diffusion length in GaN: Dislocation density and doping concentration dependence
}

\author{
K. Kumakura and T. Makimoto \\ NTT Basic Research Laboratories, NTT Corporation, 3-1 Morinosato Wakamiya, Atsugi-shi, Kanagawa $243-$ \\ 0198, Japan \\ N. Kobayashi \\ The University of Electro-Communications, 1-5-1 Chofugaoka, Chofu-shi, Tokyo 182-8585, Japan
}

T. Hashizume, T. Fukui, and H. Hasegawa

RCIQE, Hokkaido University, North 13 West 8, Sapporo 060-8628, Japan

(Received 13 April 2004; accepted 7 December 2004; published online 27 January 2005)

\begin{abstract}
We investigated the minority carrier diffusion length in $p$ - and $n$-GaN by performing electron-beam-induced current measurements of GaN $p-n$ junction diodes. Minority electron diffusion length in $p$-GaN strongly depended on the $\mathrm{Mg}$ doping concentration for relatively low dislocation density below $10^{8} \mathrm{~cm}^{-2}$. It increased from 220 to $950 \mathrm{~nm}$ with decreasing $\mathrm{Mg}$ doping concentration from $3 \times 10^{19}$ to $4 \times 10^{18} \mathrm{~cm}^{-3}$. For relatively high dislocation density above $10^{9} \mathrm{~cm}^{-2}$, it was less than $300 \mathrm{~nm}$ and independent of the $\mathrm{Mg}$ doping concentration. On the other hand, the minority hole diffusion length in $n$-GaN was shorter than $250 \mathrm{~nm}$ and less affected by the dislocation density and $\mathrm{Si}$ doping concentration. We discuss the doping-concentration and dislocation-density dependence of minority carrier diffusion length. (C) 2005 American Institute of Physics. [DOI: 10.1063/1.1861116]
\end{abstract}

The recent progress of nitride heterojunction bipolar transistors (HBTs) (Refs. 1-3) will open the door to highpower and high-temperature electronics applications. The minority carrier diffusion length in the base layer of HBTs is one of the key factors determining device characteristics. However, there have been few systematic reports on the doping concentration and dislocation density dependence of minority carrier diffusion length. Electron beam induced current (EBIC) measurements have been carried out to determine the diffusion length normal to the $c$-axis using Schottky diodes, ${ }^{4-8}$ but the Mg doping concentration dependence of electron diffusion length or the minority carrier diffusion length parallel to $c$-axis has not been reported. In addition, for EBIC measurements of $p-n$ junction diodes, ${ }^{9-11}$ the doping concentration and dislocation density dependence of the minority carrier diffusion length has not been previously reported. Considering the minority carrier transport in the base layer of HBTs, it is important to clarify the characteristics of the minority carrier parallel to the $c$-axis. Therefore, in this paper, we investigate and discuss the doping concentration and dislocation density dependence of minority carrier diffusion length parallel to the $c$-axis in Si-doped and $\mathrm{Mg}$-doped $\mathrm{GaN}$ by EBIC measurements of $\mathrm{GaN} p-n$ junction diodes.

GaN $p-n$ junction diode structures were grown by metalorganic vapor phase epitaxy (MOVPE). We used the MOVPE-grown GaN templates on $c$-face sapphire substrates or bulk GaN substrates. We grew a 1- $\mu \mathrm{m}$-thick undoped $\mathrm{GaN}$, a $1-\mu \mathrm{m}$-thick Si-doped $\mathrm{GaN}$, a $0.7-\mu \mathrm{m}$-thick $\mathrm{Mg}$ doped GaN, and a 0.3 - $\mu \mathrm{m}$-thick $\mathrm{Mg}$-doped GaN contact layer. The growth temperature was $1000{ }^{\circ} \mathrm{C}$. The dislocation density $\left(N_{\text {dis }}\right)$ of the GaN substrates was varied from $10^{6}$ to mid- $10^{7} \mathrm{~cm}^{-2}$ and that of the GaN templates from 8 $\times 10^{7}$ to $2 \times 10^{9} \mathrm{~cm}^{-2}$, respectively. The $\mathrm{Si}$ doping concentrations for $n-\mathrm{GaN}$ were $4 \times 10^{17}$ and $4 \times 10^{18} \mathrm{~cm}^{-3}$. The $\mathrm{Mg}$ doping concentration was also varied from $4 \times 10^{18}$ to 3 $\times 10^{19} \mathrm{~cm}^{-3}$. To make good Ohmic contacts, the Mg doping concentration was fixed at $3 \times 10^{19} \mathrm{~cm}^{-3}$ for the $p$-type contact layer. After the growth, all samples were annealed at $700{ }^{\circ} \mathrm{C}$ in nitrogen to obtain $p$-type conduction. Separate variable-temperature Hall effect measurements showed that the hole concentration of the $\mathrm{Mg}$-doped $\mathrm{GaN}$ at room temperature was around $1-3 \times 10^{17} \mathrm{~cm}^{-3}$ under these $\mathrm{Mg}$ doping concentrations, and that the acceptor concentration was above $10^{18} \mathrm{~cm}^{-3}$, indicating that the depletion layer in $p$-GaN is $60-\mathrm{nm}$-thick at most.

The $p-n$ junction diode structures were fabricated using the standard photolithographic technique and electron cyclotron resonance plasma etching. The Ohmic metals for $n$ - and $p$-GaN were $\mathrm{Al} / \mathrm{Au}$ and $\mathrm{Ni} / \mathrm{Au}$, respectively. All metals were deposited by electron beam evaporation after the surface oxides had been removed by an $\mathrm{HCl}$ solution. The samples were cleaved and then mounted on a stage of a scanning electron microscope (SEM). EBIC measurements were carried out with the SEM system equipped with a current amplifier unit (HITACHI S-4100). The electron beam scanned the cleaved surface perpendicular to the plane of the $p-n$ junction. The electron-beam acceleration voltage $V_{\text {acc }}$ was $10 \mathrm{kV}$. Since the lateral size of excitation volume was proportional to the $V_{\text {acc }}^{1.75}$, ${ }^{12}$ the low acceleration voltage is preferable to improve the measurement resolution. On the other hand, an electron-beam with a low acceleration voltage will produce electron-hole pairs close to the surface, making the effect of surface recombination worse. Cathodoluminescence (CL) measurements have revealed that the CL intensity of GaN band edge emission drastically decreases for acceleration voltages less than $10 \mathrm{kV} .{ }^{13}$ This indicates that the generated electron-hole pairs were strongly affected by the surface state, that is, the surface recombination, for acceleration voltages of less than $10 \mathrm{kV}$. Therefore, the acceleration voltage was chosen to be $10 \mathrm{kV}$ to achieve high reso- 


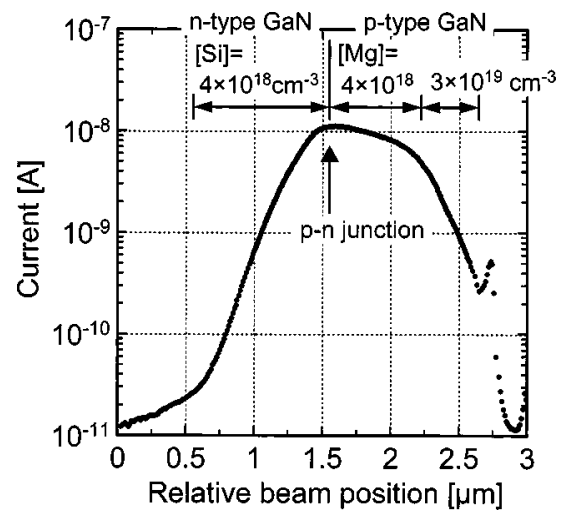

FIG. 1. Typical line scan profile obtained by EBIC measurement.

lution and to decrease the effect of surface recombination. Under these measurement conditions, the resolution of the EBIC measurements was estimated to be better than $50 \mathrm{~nm}$. Figure 1 shows the typical line scan profile obtained by the EBIC measurement. We determined the minority carrier diffusion length $L$ by least-square fitting the obtained EBIC profiles to the simple equation $I \propto \exp (-x / L)$, where $I$ is the total collected current and $x$ is the relative beam position. ${ }^{14}$

Figure 2 shows the minority electron diffusion length in $\mathrm{Mg}$-doped $\mathrm{GaN}$ as a function of the dislocation density. Solid squares and open and solid circles correspond to the $\mathrm{Mg}$ doping concentration of $4 \times 10^{18}, 1 \times 10^{19}$, and 3 $\times 10^{19} \mathrm{~cm}^{-3}$, respectively. For relatively low dislocation density below $10^{8} \mathrm{~cm}^{-2}$, the minority electron diffusion length depended on the $\mathrm{Mg}$ doping concentration and was almost constant irrespective of the dislocation density. The diffusion length drastically increased with decreasing $\mathrm{Mg}$ doping concentration. Its values were around 220,700, and $950 \mathrm{~nm}$ for the $\mathrm{Mg}$ doping concentration of $3 \times 10^{19}, 1 \times 10^{19}$, and 4 $\times 10^{18} \mathrm{~cm}^{-3}$, respectively. On the other hand, for relatively high dislocation density above $10^{8} \mathrm{~cm}^{-2}$, it is clear that the diffusion length decreased with increasing dislocation density. The diffusion lengths were around $300 \mathrm{~nm}$ or less even though the $\mathrm{Mg}$-doping concentration was relatively low, 4 $\times 10^{18} \mathrm{~cm}^{-3}$.

For relatively low dislocation density below $10^{8} \mathrm{~cm}^{-2}$, the average period of dislocation was considered to be large enough $(>1 \mu \mathrm{m})$ compared with the minority electron diffusion length. Therefore, the dominant recombination mechanism for minority electrons might not have been the

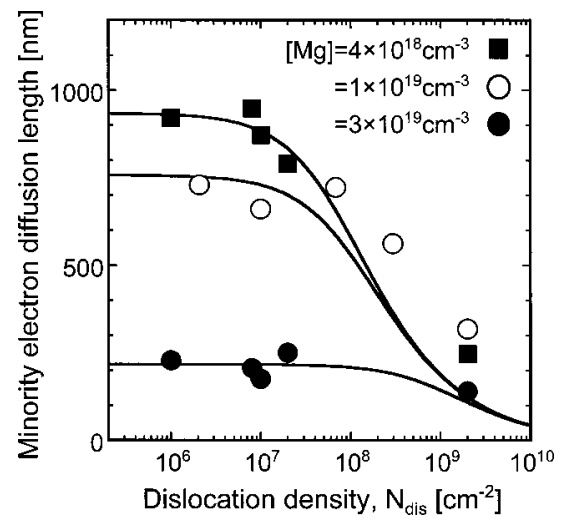

FIG. 2. The minority electron diffusion length in Mg-doped GaN as a function of the dislocation density. The solid curves were obtained by fitting to the experimental data. electron one due to the low hole mobility and/or short life-
Downloaded 24 Feb 2006 to 133.87.26.100. Redistribution subject to AlP license or copyright, see http://apl.aip.org/apl/copyright.jsp

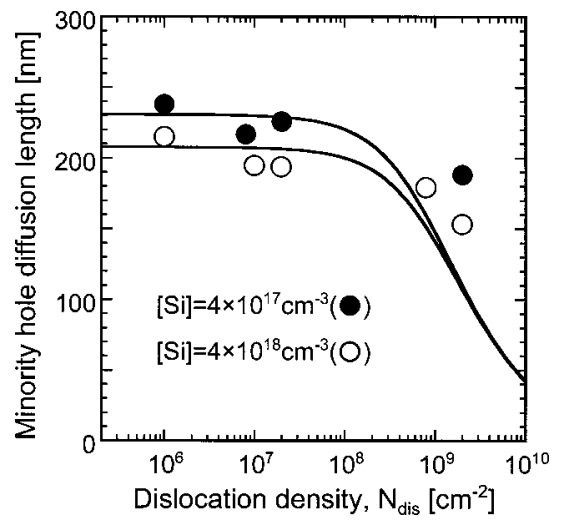

FIG. 3. The minority hole diffusion length in Si-doped GaN as a function of the dislocation density. The solid curves were obtained by fitting to the experimental data.

dislocations, but Mg-related impurities. It is expected that a nearest-neighbor associate of an isolated $\mathrm{Mg}$ atom in the $\mathrm{Ga}$ site and a nitrogen vacancy as well as the acceptor is formed in $\mathrm{GaN}$ when $\mathrm{Mg}$ is heavily doped above $10^{19} \mathrm{~cm}^{-3}$ into $\mathrm{GaN}$ in MOVPE growth. These associates act as deep donors. The deep donors partially compensate the acceptors, so-called "self-compensation," resulting in the degradation of the electrical properties of Mg-doped $\mathrm{GaN}$, such as decreased carrier mobility. Therefore, the minority electron diffusion length depended strongly on the $\mathrm{Mg}$ doping concentration for relatively low dislocation density below $10^{8} \mathrm{~cm}^{-2}$. On the other hand, for relatively high dislocation density above $10^{8} \mathrm{~cm}^{-2}$, the minority electron diffusion length did not depend on $\mathrm{Mg}$ doping concentration, but on the dislocation density in $\mathrm{GaN}$. The average distance between dislocations is about $220 \mathrm{~nm}$ at the dislocation density of 2 $\times 10^{9} \mathrm{~cm}^{-2}$, where the minority carrier diffusion length was smaller than $300 \mathrm{~nm}$, irrespective of the $\mathrm{Mg}$ doping concentration. This means that minority electrons recombined at dislocations, resulting in the minority electron diffusion length being limited by the dislocation density at relatively high dislocation densities, in particular, above $10^{9} \mathrm{~cm}^{-2}$.

In EBIC measurements under low acceleration voltage below $20 \mathrm{kV}$, almost all reported values of minority electron diffusion length in Mg-doped $\mathrm{GaN}$ are less than $300 \mathrm{~nm} .{ }^{6,7,9,10}$ The relatively short electron diffusion length can be ascribed to the heavy $\mathrm{Mg}$ doping above $10^{19} \mathrm{~cm}^{-3}$ or relatively high dislocation density above $10^{9} \mathrm{~cm}^{-2}$ in $\mathrm{GaN}$.

Figure 3 shows the minority hole diffusion length in $\mathrm{Si}$ doped $\mathrm{GaN}$ as a function of the dislocation density. Solid and open circles correspond to the Si doping concentration of 4 $\times 10^{17}$ and $4 \times 10^{18} \mathrm{~cm}^{-3}$, respectively. The minority hole diffusion length was almost constant for low dislocation density below $10^{8} \mathrm{~cm}^{-2}$, and slightly decreased above the dislocation density of $10^{9} \mathrm{~cm}^{-2}$. The hole diffusion length also slightly decreased with increasing Si doping concentration. A number of studies have predicted and confirmed negative charges located at the core of edge dislocations. ${ }^{11,15}$ These dislocations might act as hole traps, which would decrease the hole diffusion length. However, in the present work, the hole diffusion length was almost constant and its value was less than $250 \mathrm{~nm}$ even in the low dislocation density and low $\mathrm{Si}$ doping concentration. These results indicate that the minority hole diffusion length is essentially shorter than the electron one due to the low hole mobility and/or short life-
AIP license or copyright, see http://apl.aip.org/apl/copyright.jsp 
TABLE I. Summary of fitting results from EBIC measurements.

\begin{tabular}{lcccc}
\hline \hline Sample & $\begin{array}{c}\text { Doping } \\
\text { concentration }\left(\mathrm{cm}^{-3}\right)\end{array}$ & $\begin{array}{c}\text { Minority } \\
\text { carrier }\end{array}$ & $\begin{array}{c}\text { Mobility } \\
{\left[\mathrm{cm}^{2} / \mathrm{V} \mathrm{s}\right]}\end{array}$ & $\begin{array}{c}\text { Lifetime } \\
\left(\tau_{0}\right)(\mathrm{ns})\end{array}$ \\
\hline$p-\mathrm{GaN}$ & $4 \times 10^{18}$ & electron & 139 & 2.4 \\
$p-\mathrm{GaN}$ & $1 \times 10^{19}$ & electron & 113 & 2.0 \\
$p-\mathrm{GaN}$ & $3 \times 10^{19}$ & electron & 32 & 0.6 \\
$n-\mathrm{GaN}$ & $4 \times 10^{17}$ & hole & 26 & 0.8 \\
$n-\mathrm{GaN}$ & $4 \times 10^{18}$ & hole & 23 & 0.7 \\
\hline \hline
\end{tabular}

time. Therefore, minority holes are less affected by dislocations and impurities, as shown in Fig. 3.

Bandić et al. have reported a simple model for minority carrier lifetime as a function of the dislocation density. ${ }^{16}$ They assume that linear dislocations are distributed in a hexagonal "honeycomb-type" array. The minority carrier lifetime, due to recombination at the dislocations $\left(\tau_{\text {dis }}\right)$ was obtained by solving the diffusion equation using the parameters of the diffusivity $(D)$ and the radius of the dislocation. If we assume that the lifetime without recombination at the dislocations is given by $\tau_{0}$, then the total minority carrier lifetime is represented by $\tau^{-1}=\tau_{0}^{-1}+\tau_{\text {dis }}^{-1}$. The minority carrier diffusion length $L$ were obtained by the equation $L=\sqrt{D \tau}$ $=\sqrt{\left(k_{B} T \mu / e\right) \tau}$ (utilizing the Einstein relationship between $D$ and $\mu$ ), where $k_{B}$ is the Boltzman constant, $T$ is temperature, $\mu$ is the mobility. The mobility depends on the doping concentration due to carrier scattering at the ionized dopants. Therefore, the minority carrier diffusion length was affected by the dislocation density and the doping concentration. The electrical properties of the dislocations has been characterized by scanning Kelvin force microscope. ${ }^{17}$ Considering the tip radius of the probe and the tip-induced depletion, the radius of the dislocation core was estimated to be around $10 \mathrm{~nm}$. Therefore, we assumed that the dislocation radius was $10 \mathrm{~nm}$. According to the model described above, we fitted the experimental data. The solid curves in Figs. 2 and 3 show the fitting results, obtained by varying the mobility $\mu$ and the lifetime without scattering at the dislocation $\tau_{0}$. Table I summarizes the fitting results from EBIC measurements. The minority electron mobilities were calculated to be 139 , 113 , and $32 \mathrm{~cm}^{2} / \mathrm{V} \mathrm{s}$ for the Mg-doping concentrations of $4 \times 10^{18}, 1 \times 10^{19}$, and $3 \times 10^{19} \mathrm{~cm}^{-3}$, respectively. The electron lifetimes without scattering at the dislocation were 2.4, 2.0 , and $0.6 \mathrm{~ns}$, respectively. The mobility drastically decreased at the heavy Mg-doping concentration of 3 $\times 10^{19} \mathrm{~cm}^{-3}$, indicating that the electrical properties of $\mathrm{Mg}$ doped $\mathrm{GaN}$ were degraded as described before. In Si-doped GaN for the dislocation density below $10^{9} \mathrm{~cm}^{-2}$, it was reported that the majority electron mobility is mainly limited not by the dislocation density but by the doping concentration. ${ }^{18}$ The mobility values decrease with increasing the Si-doping concentration, and they are 170, 100, and $60 \mathrm{~cm}^{2} / \mathrm{V} \mathrm{s}$ for the carrier concentration of $4 \times 10^{18}, 1$ $\times 10^{19}$, and $6 \times 10^{19} \mathrm{~cm}^{-3}$, respectively. ${ }^{18}$ These reported majority electron mobility values agree with the minority electron mobility values derived from the EBIC results. On the other hand, the minority hole mobilities were calculated to be 26 and $23 \mathrm{~cm}^{2} / \mathrm{V}$ s for the Si-doping concentrations of $4 \times 10^{17}$ and $4 \times 10^{18}$, respectively. Both lifetimes without scattering at the dislocation were $0.7-0.8 \mathrm{~ns}$. It was reported that the majority hole mobility values in $\mathrm{Mg}$-doped $\mathrm{GaN}$ are 22 and $13 \mathrm{~cm}^{2} / \mathrm{V}$ s for the hole concentration of $3 \times 10^{17}$ and
$1 \times 10^{18} \mathrm{~cm}^{-3}$ and their Mg-doping concentration of 1.6 $\times 10^{19}$ and $8 \times 10^{19} \mathrm{~cm}^{-3}$, respectively. ${ }^{19}$ The reported majority hole mobility values agree with the minority hole mobility values derived from the EBIC results.

This result indicates that the minority hole essentially has the lower mobility and shorter lifetime than those of minority electron. The relatively large hole mobility compared with the majority hole mobility in $p-\mathrm{GaN}$ was ascribed to the lower impurity concentration in Si-doped GaN than that in Mg-doped GaN (above $10^{19} \mathrm{~cm}^{-3}$ ).

In summary, we have investigated the doping concentration and dislocation density dependence of minority carrier diffusion length parallel to the $c$-axis by EBIC measurements of $\mathrm{GaN} p-n$ junction diodes. The diode structures were grown by MOVPE on GaN with various dislocation densities. $\mathrm{Mg}$ and Si doping concentrations were varied to investigate the influence of the impurities on the minority carrier diffusion length. Minority electron diffusion length depended on the $\mathrm{Mg}$ doping concentration at relatively low dislocation density and was limited by the dislocation density at relatively high dislocation densities. On the other hand, the hole diffusion length was less affected by the dislocation density and the Si doping concentration, showing that hole diffusion length was essentially shorter than the electron one. A simple model for the minority carrier lifetime including recombination at dislocations gave a good fit to the experimental results.

The authors thank Associate Professors Seiya Kasai of Hokkaido University for his fruitful discussions. They are grateful to Dr. Yoshiro Hirayama, Dr. Hideaki Takayanagi, and Dr. Sunao Ishihara for their encouragement throughout this work.

${ }^{1}$ T. Makimoto, K. Kumakura, and N. Kobayashi, Appl. Phys. Lett. 79, 380 (2001).

${ }^{2}$ K. Kumakura, T. Makimoto, and N. Kobayashi, Appl. Phys. Lett. 80, 3841 (2002).

${ }^{3}$ T. Makimoto, K. Kumakura, and N. Kobayashi, Appl. Phys. Lett. 83, 1035 (2003).

${ }^{4}$ L. Chernyak, A. Osinsky, H. Temkin, J. W. Yang, Q. Chen, and M. A. Khan, Appl. Phys. Lett. 69, 2531 (1996).

${ }^{5}$ Z. Z. Bandić, P. M. Bridger, E. C. Piquette, and T. C. McGill, Appl. Phys. Lett. 72, 3166 (1998).

${ }^{6}$ Z. Z. Bandić, P. M. Bridger, E. C. Piquette, and T. C. McGill, Appl. Phys. Lett. 73, 3276 (1998).

${ }^{7}$ P. M. Bridger, Z. Z. Bandić, E. C. Piquette, and T. C. McGill, Appl. Phys. Lett. 73, 3438 (1998).

${ }^{8}$ L. Chernyak, A. Osinsky, G. Nootz, A. Schulte, J. Jasinski, M. Benamara, Z. Liliental-Weber, D. C. Look, and R. J. Molnar, Appl. Phys. Lett. 77, 2695 (2000).

${ }^{9}$ T. Miyajima, M. Ozawa, T. Asatsuma, H. Kawai, and M. Ikeda, J. Cryst. Growth 189/190, 768 (1998).

${ }^{10}$ L. Chernyak, G. Nootz, and A. Osinsky, Electron. Lett. 37, 922 (2001).

${ }^{11}$ A. F. Wright and U. Grossner, Appl. Phys. Lett. 73, 2751 (1998).

${ }^{12}$ H. J. Leamy, J. Appl. Phys. 53, R51 (1982).

${ }^{13}$ F. Ishikawa and H. Hasegawa, Appl. Surf. Sci. 212-213, 885 (2003).

${ }^{14} \mathrm{~J}$. W. Orton and P. Blood, The Electrical Characterization of Semiconductors: Measurement of Minority Carrier Properties (Academic, San Diego, 1990).

${ }^{15}$ B. S. Simpins, E. T. Yu, P. Waltereit, and J. S. Speck, J. Appl. Phys. 94, 1448 (2003).

${ }^{16}$ Z. Z. Bandić, P. M. Bridger, E. C. Piquette, and T. C. McGill, Solid-State Electron. 44, 221 (2000).

${ }^{17}$ E. T. Yu, E. J. Miller, D. M. Schaadt, and B. S. Simpkins, Collected Abstract of 2003 International Symposium on Compound Semiconductors (2003 ISCS), TuA1.1, San Diego, 2003.

${ }^{18}$ H. M. Ng, D. Doppalapudi, T. D. Moustakas, N. G. Weimann, and L. F. Eastman, Appl. Phys. Lett. 73, 821 (1998).

${ }^{19}$ P. Kozodoy, H. Xing, S. P. DenBaas, U. K. Mishra, A. Saxler, R. Perrin, S. Elhamri, and W. C. Mitchel, J. Appl. Phys. 87, 1832 (2000). 